\title{
TIRE RUBBER TESTING PROCEDURE OVER A WIDE RANGE OF STRAIN RATES
}

\author{
PAWEŁ BARANOWSKI \\ Military University of Technology, Faculty of Mechanical Engineering, Warsaw, Poland \\ e-mail: pawel.baranowski@wat.edu.pl \\ JACEK JANISZEWSKI \\ Military University of Technology, Faculty of Mechatronics and Aviation, Warsaw, Poland \\ e-mail: jacek.janiszewski@wat.edu.pl \\ JERZY MAŁACHOWSKI \\ Military University of Technology, Faculty of Mechanical Engineering, Warsaw, Poland \\ e-mail: jerzy.malachowski@wat.edu.pl
}

\begin{abstract}
The main aim of the paper is to present the procedure allowing one to determine correct mechanical characteristics of a rubber material compressed within a wide range of strain rates. In order to obtain a satisfactory wide spectrum of material data, a number of tests were conducted both under low and high strain rates with the use of a universal strength machine and split Hopkinson pressure bar set-up equipped with polymethyl methacrylate and 7075T6 alloy bars. During the investigations, the necessity of performing pre-compression tests and the problem of specimen geometry were pointed out as key methodical requirements to guarantee achieving valid experimental data both from quasi-static and high strain rate tests.
\end{abstract}

Keywords: tire rubber, uniaxial compression test, SHPB test, strain rates, spectral analysis

\section{Introduction}

Nowadays, rubber is considered as one of the most important materials for many applications. Its mechanical characteristics, including ability to reversible deformation under loading of mechanical forces, result in the fact that various forms of rubber are very popular in many industries. Elastomeric structures, due to their low stiffness modulus and high damping characteristics, are used to absorb energy in dynamic (impulse or impact) loadings as isolation bearings, shock absorbers, etc. For example, the automotive industry, often uses materials and rubber-based composites to produce tires with high strength and durability. Nevertheless, development of the pneumatic tire structure with a high operating standard is associated with carrying out a series of experimental studies for determining stability and reliability of its implementation. Numerical modelling using the Finite Element Method (FEM), which is found to be a very useful and effective tool for deformation and stress state analysis in the tire structure (Helnwein et al., 1993; Reid et al., 2007), is an alternative to experimental testing. Thus, for effective and correct analyses, its numerical model should be developed with particular attention and care. Therefore, an accurate assessment of mechanical properties of the tire rubber in various operational conditions is essential in the tire numerical modelling (Malachowski et al., 2007).

It can be observed that mechanical properties of rubber and rubber-like materials have been effectively determined and understood over the past decades. Such materials were examined using static experimental tests (Gent, 1994; Szurgott et al., 2012; Sridharan and Sivaramakrishnan, 2013), as well as fatigue testing was performed by many authors (Kim and Jeong, 2005; Saintier 
et al., 2006; Zine et al., 2006). Static experimental tests for both tension and compression are usually carried out on universal strength machines. During testing, the rubber material exhibits nonlinear stress distribution and its behaviour considerably changes. When a rubber specimen is compressed, its contact area increases drastically and a friction effect can be clearly observed, manifested as a barrelling effect. Therefore, it is intended to reduce friction as much as possible using lubricants or water (Nakajima and Takahashi, 2002).

Recently, behaviour of rubber under high-strain rates loading has been more thoroughly investigated with compression, tension or shear characteristics taking into consideration (Giovanola, 1988; Lindholm and Yeakley, 1968; Nicholas, 1981; Roland, 2006; Song and Chen, 2003). It resulted from the fact that many types of elastomers (e.g. rubber, polyuera) were applied as blast/ballistic protection materials in combat vehicles (Auckland et al., 2013; Roland et al., 2010). The specific properties of elastomers, such as: high toughness-to-density ratio, capability to accommodate large deformations and their high damping characteristics, make them suitable for employment in the dissipation of kinetic energy coming from impacts and shocks.

A device most commonly used for investigating the dynamic behaviour of solid materials at high strain rates within the range of $10^{2}$ to $10^{4} \mathrm{~s}^{-1}$ is the Kolsky bar, more commonly known as split Hopkinson pressure bar (SHPB) named after Bertram Hopkinson (Chen et al., 2000, 2011; Song and Chen, 2005; Ellwood et al., 1982; Gray, 1994; Hopkinson, 1904; Hopkinson, 1872; Janiszewski, 2012; Meyers, 1994). It is used to obtain stress-strain curves of investigated materials for certain strain rates. The basic test using SHPB is a compression test, where a cylindrical specimen is deformed between two flat surfaces of the bars (input and output, or incident and transmitted). If the tested material is a soft material, such as an elastomer, the applicability of the conventional SHPB technique needs to be carefully examined to meet methodical requirements (stress equilibrium in the specimen, constant strain rate conditions during the test) and to solve many technical and methodological problems. These problems arise mainly because the transmitted signal may be too weak to be measured, which results from large mismatch of impedance between the specimen and the metallic bars. The specimen thickness also influences the attenuation of the transmitted signal since a stress wave propagates in soft materials with a relatively low velocity. Due to these limitations, many modifications of the conventional SHBP technique were developed.

The simplest approach is to increase sensitivity of the gauges recording the transmitted pulse. Chen et al. (1999) used piezoelectric quartz gauges embedded on the aluminium bars. An other method includes reduction of mechanical impedance differences between the bars and the specimen using mainly three options: (1) modifying cross section of the specimen, (2) altering cross section of the pressure bar, e.g. using a hollow transmission bar (Zhao et al., 1997) and (3) changing the material of the pressure bars, e.g. by replacing metals bars with polymeric bars (Casem et al., 2003). The latter is frequently chosen by many investigators.

The substitution of polymeric bars with metallic ones, however, causes many problems due to the viscoelastic nature of the polymer material (Wang et al., 1994; Zhao et al., 1997). For metal bars, it can be assumed that elastic wave signals, which are determined from the strain measured by strain gauges, are not only known at the measuring points but everywhere along the bar. Therefore, the transmitted wave can be shifted to the transmitted bar-specimen interface to calculate the transmitted force and velocity, whereas the incident force and velocity can be obtained from incident and reflected signals shifted to the incident bar-specimen interface. Unfortunately, this procedure is not valid for polymeric bars because of the attenuation and dispersion of the wave pulse during its propagation along the bar. Therefore, the correction of the wave signals is necessary in the case of a viscoelastic SHPB.

There are two approaches to correction of the wave signals. The first method is based on a theoretical viscoelastic constitutive equation and a characteristics theory of wave propagation (Bacon, 1998). An alternative approach is to use spectral analysis to correct wave pulses (Cheng 
et al., 1998; Zhao et al., 1997; Duyle, 1989). In this paper, spectral analysis and a wave shifting procedure are applied to a PMMA split Hopkinson pressure bar setup.

All the facts described above were included and taken into consideration in the authors' experimental tests. The present paper describes - in a comprehensive way - the procedure of determining correct mechanical characteristics of a selected rubber material deformed within a wide range of strain rates. The paper is organized as follows: Section 2 is devoted to the description of quasi-static compression testing of tire rubber. In this Section, the procedure of performed tests under low strain rates and the stress-strain curves obtained are presented. In Section 3, the study of rubber properties under high strain deformation rates is described. Particular emphasis is placed on presenting the specificity of performing mechanical tests under dynamic loading with the use of aluminium alloy and polymethyl methacrylate (PMMA) bars system.

The genesis of the paper is related to the recent events including many world military operations, where the Improvised Explosive Devices (IED) are commonly used on the battlefield. IED explosions can destroy wheels or even the suspension system which makes the vehicle unable to drive (Borkowski and Motrycz, 2012). Its destructive effect results in tire tearing followed by large deformation of other elements of the suspension system. Such problems are also simulated using numerical methods (Baranowski et al., 2011; Baranowski and Malachowski, 2015). However, the authors found lack of material data of tire rubber in terms of tire numerical simulations under dynamic loading conditions, especially blast waves. Possessing a wide range of the stressstrain curves within a number of strain rates and a proper constitutive model, the modelling and simulation of different problems will ensure that the obtained results are correct and close to the real findings

\section{Quasi-static tests}

Quasi-static compression tests were carried out using MTS Criterion C45.105 electromechanical universal test machine. The specimens were compressed with three different strain rates: $0.001 \mathrm{~s}^{-1}, 0.01 \mathrm{~s}^{-1}$ and $1.00 \mathrm{~s}^{-1}$. Cylindrical specimens were prepared with a diameter-to-height ratio according to ASTM D575-91 standard (D575-91 ASTM 2001). The specimens with $8.10 \mathrm{~mm}$ height and $17.60 \mathrm{~mm}$ diameter were cut out from the tire using the water jet cutting technique.

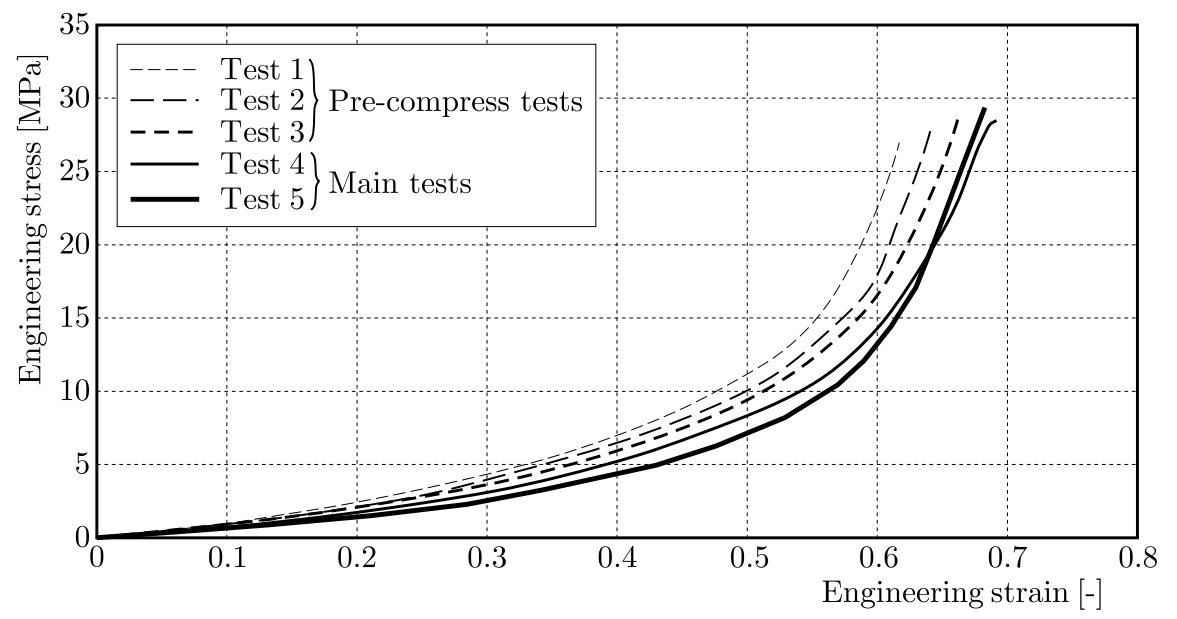

Fig. 1. Stress-strain curves for one specimen with pre-compression tests (strain rate of $1.0 \mathrm{~s}^{-1}$ )

Friction between the specimens and compressing grip surfaces was reduced using a lubricant, however, a barrelling effect was not completely omitted, which was negligible. In Fig. 1, 
exemplary stress-strain curves from five compression tests of the same specimen are presented for a chosen strain rate $1.0 \mathrm{~s}^{-1}$. In this case, an interesting phenomenon, which was also noticed during the dynamic SHPB testing, was observed.

It can be observed that the curves from tests 1-4 differ from each other, whereas the curves from tests 4 and 5 are similar. It is noticed that the specimen after "pre-compression" behaves repetitively and gives nearly coincident stress-strain curves for the same conditions of the tests, even for large deformation. Such a phenomenon can be caused by changes initiated in the material structure. In all probability, during the first pre-compression tests, crosslinks and polymer chains which transfer most of the force break up. In the next tests (\#4 and \#5), when the load is applied and the crosslinks as well as chains are broken, only particles (molecules, globules) accommodate the compression force (Fig. 2). Similar rubber structure phenomena were also discussed in (Pouriayevali and Shim, 2012). The pre-compressed behaviour was confirmed in five tests for a strain rate of $1.00 \mathrm{~s}^{-1}$, therefore, in two other cases, each specimen was loaded only four times (the fourth curve was considered as the proper one). From the uniaxial compression test at three quasi-static rates of strain, the engineering stress vs. engineering strain curves were obtained, as presented in Fig. 3.

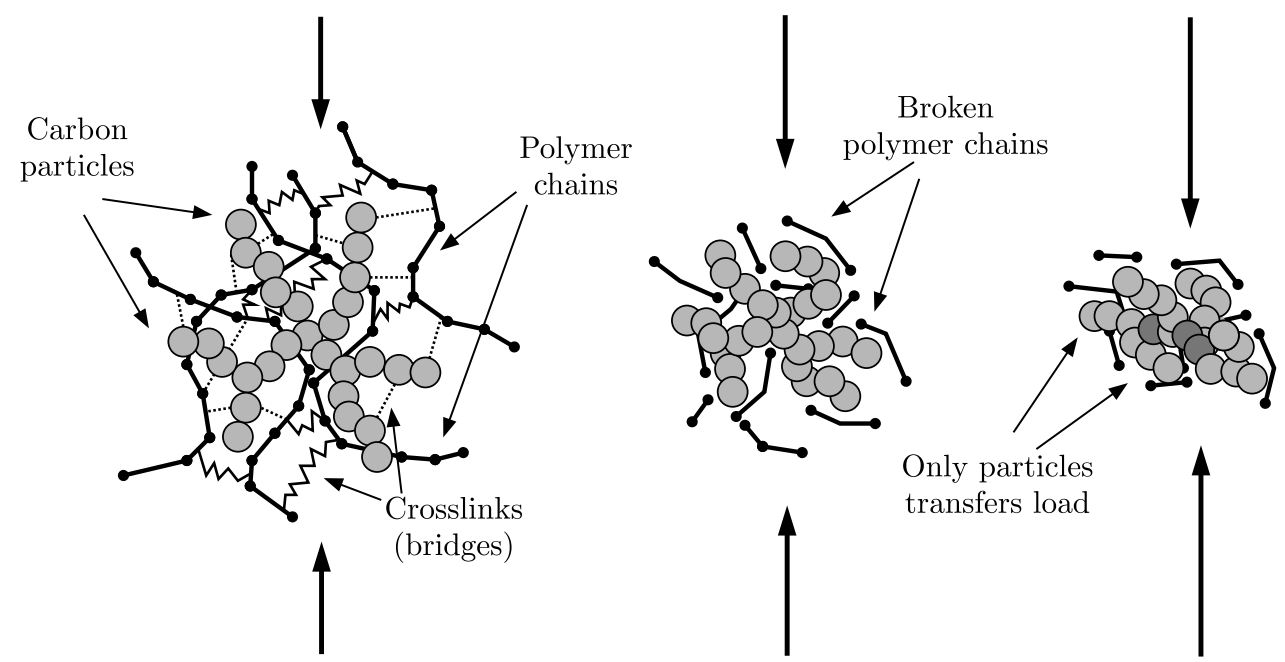

Fig. 2. Likely change of a rubber structure during compression (Pouriayevali and Shim, 2012)

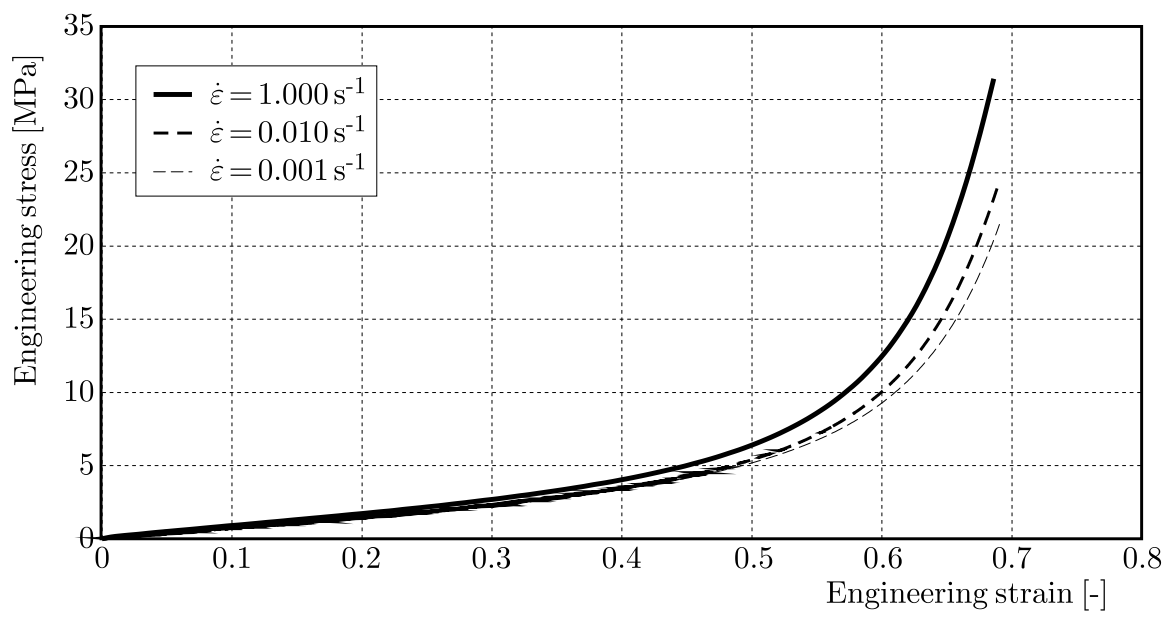

Fig. 3. Average stress-strain curves calculated from the obtained results

The carried out tests revealed a strain rate dependency on the tested rubber material samples, which is clearly visible in Fig. 1. Comparison of the results from papers by Gent (1994), 
Pouriayevali and Shim (2012), Sridharan and Sivaramakrishnan (2013), Szurgott et al. (2012) confirms the authors' belief that the material mechanical data are correct and provide the basis for a theorem that the investigated material behaviour is different under dynamic loading conditions with various strain rates. In fact, the next Section confirms it.

\section{Dynamic SHPB tests}

\subsection{Experimental set-up}

The rubber testing at higher strain rates was carried out with the use of a classical compression SHPB arrangement (Fig. 4), which consists mainly of a loading device (an air pressure gun), bar components (a striker, input and output bars), a striker velocity measurement system (Micro-Epsilon optoCONTROL1200 with dynamic resolution $50 \mu \mathrm{m}$ ) and a data acquisition system.

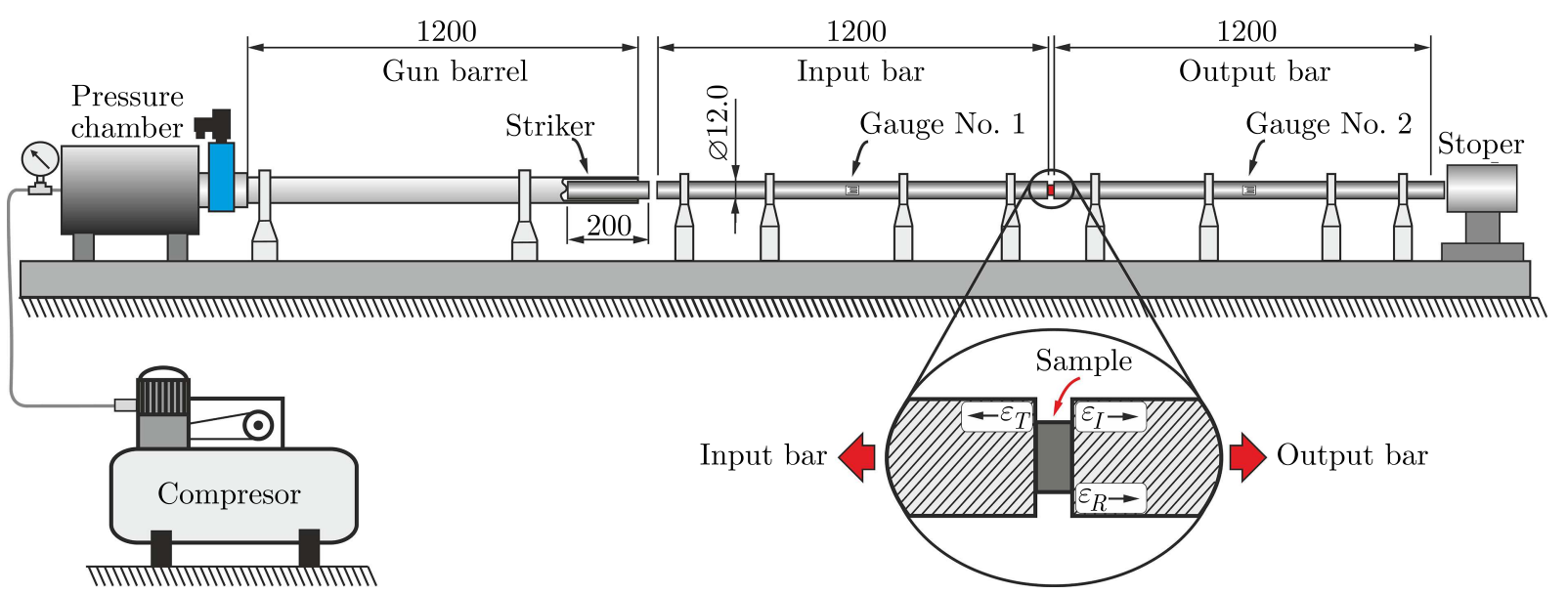

Fig. 4. Scheme of SHPB apparatus used in investigations

The bars were $1200 \pm 0.5 \mathrm{~mm}$ long each, while the striker length was $200 \pm 0.1 \mathrm{~mm}$. All three bars had the diameter of $12.0 \mathrm{~mm}$. The input and output bars were supported by four linear bearing stands which were mounted on an optical bench allowing precise alignment of the bars system. For tire rubber testing, low impedance bar materials, i.e. PMMA and Al 7075-T6 were used to avoid large mismatch between the material impedance and the impedance of the soft material tested (Chen et al., 1999, 2000). However, the purpose of using pressure bars made of different materials was to compare the two set-ups and to make recommendations for future SHPB testing of soft materials.

For both bar materials, the wave signals in the incident and transmitted bars were captured using a pair of strain gauges attached symmetrically to the opposite surfaces of the bars and in their middle length. The strain gauges were connected to the opposite legs of the Wheatstone bridge, which was a half bridge configuration. In the other legs of the bridge, the dummy resistors were mounted, the resistance of which matched the strain gauges resistance. Typical electrical strain gauges of $1.6 \mathrm{~mm}$ gauge length were used (CEA-13-062UW-350, Vishay Micro Measurements). The amplified signals of the strain gauges were recorded using a signal conditioning unit with frequency band of $1 \mathrm{MHz}$ (SGA-0B V5 Wheatstone bridge with signal conditioning amplifiers, ESA Messtechnik) and a data acquisition system (LeCroy WJ354A high-speed digital oscilloscope).

The raw signals from the strain gauges conditioned with the applied measuring equipment are shown in Fig. 5a for aluminium alloy bars configuration, and in Fig. 5b for PMMA bars 
set-up. As it can be observed in these figures, the wave signal profiles recorded in the aluminium alloy bars differ significantly in comparison to profiles in the PMMA bars. In the case of aluminium alloy set-up, the pulse generated by the impact of the striker on the incident bar has a nearly rectangular profile with visible oscillations, called Pochhammer-Chree oscillations, which are a result of geometry dispersion. It is an undesirable effect, which leads to waveform distortion as the wave propagates over a distance. Nonetheless, dispersion effects for the considered aluminum alloy bars configuration is not significant due to the large ratio of the wavelength to bar diameter, and it may be neglected (waveforms of incident and transmitted pulses are consistent). Unfortunately, it cannot be stated for the PMMA bars. In this case, the viscoelastic nature of wave propagation in the PMMA rods is clearly evident by a longer time (due to PMMA damping properties), attenuation (amplitude decreasing) and signals dispersion (waveform changing). Therefore, numerical correction of the wave signals is necessary. In the present paper, the correction procedure of viscoelastic wave signals for PMMA bars was adopted from papers by Bacon (1998), Butt and Zue (2013), Cheng et al. (1998), Franz et al. (1984), Zhao and Gary (1995) and was discussed in an other paper by Janiszewski et al. (2016). Briefly, this procedure was as follows:

- use a proper time window to digitize the wave signal from each strain gauge position,

- apply the FFT to obtain a frequency spectrum for the digitalized wave signals,

- identify the attenuation factor ?n and wave number kn for each frequency component of the wave,

- for a selected position of xc (e.g. front surface of specimen), construct a frequency spectrum for the wave to be corrected or predicted from the measured wave signal,

- use the IFFT algorithm to obtain the corrected or predicted wave signal for the given position.

(a)

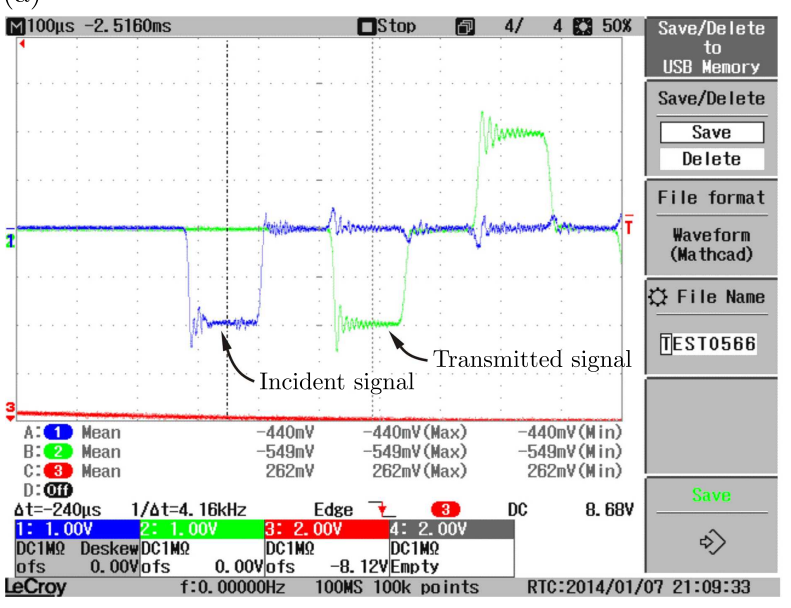

(b)

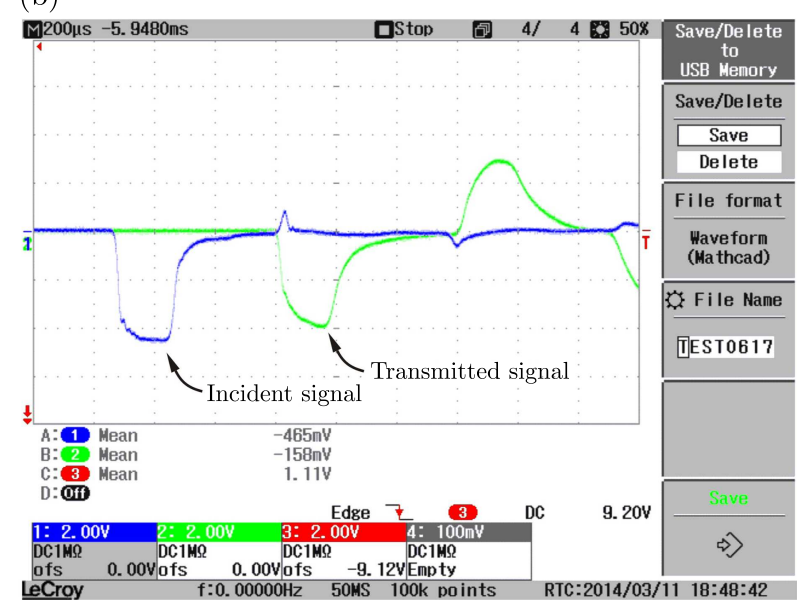

Fig. 5. Raw wave signals measured by strain gauges: (a) incident and reflected signals for aluminium alloy bars; (b) incident and transmitted signals for PMMA bars

To minimalize wave disturbances (oscillations) caused by dispersion and also to control loading conditions to facilitate stress equilibrium in the specimen, pulse shapers were used, i.e. small disks with $4.00 \mathrm{~mm}$ in diameter and $0.30 \mathrm{~mm}$ in thickness made of polyethylene sheet and $5.56 \mathrm{~mm}$ in diameter with $0.30 \mathrm{~mm}$ in thickness made of Cu-ETP copper sheet for PMMA and Al7075-T6 bars configuration, respectively. The wave shapers were placed on the impact end of the input bar with the use of lubricant (molybdenum disulphide - $\mathrm{MoS}_{2}$ ), which was also added between the specimens and the input and output bars. Application of the wave shapers was revealed especially by an increase in the rise time of incident pulses and smoothing waveform 
(Fig. 6). Moreover, the copper pulse shapers applied in the aluminium alloy bar system facilitated constant strain rate deformation in the specimen. One can also noticed that the rise time of the transmitted signal in both cases (PMMA and Al7075-T6 setups) was longer than the loading time of the incident signals. This was due to the fact that its profile and shape depended on high-strain rate behaviour of the specimen material, whereas properties of incident signal were affected by the shaper (geometry, material) and material of the bars.

(a)

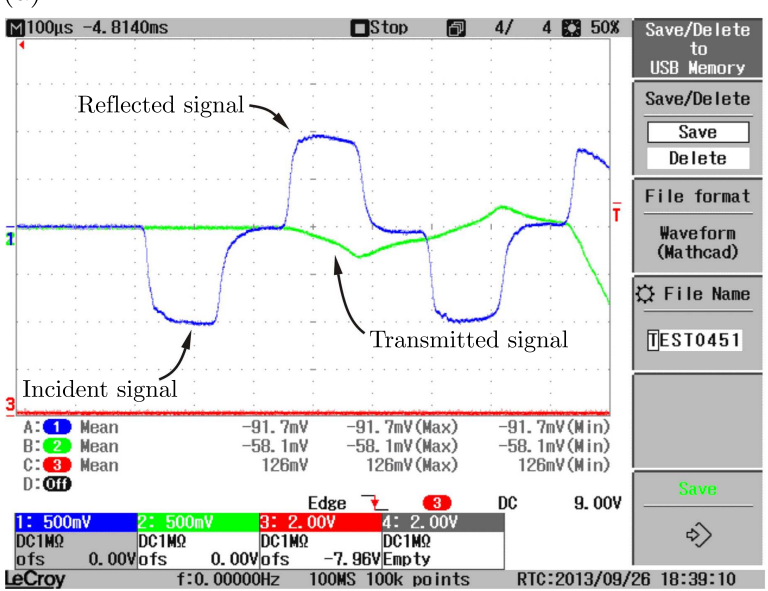

(b)

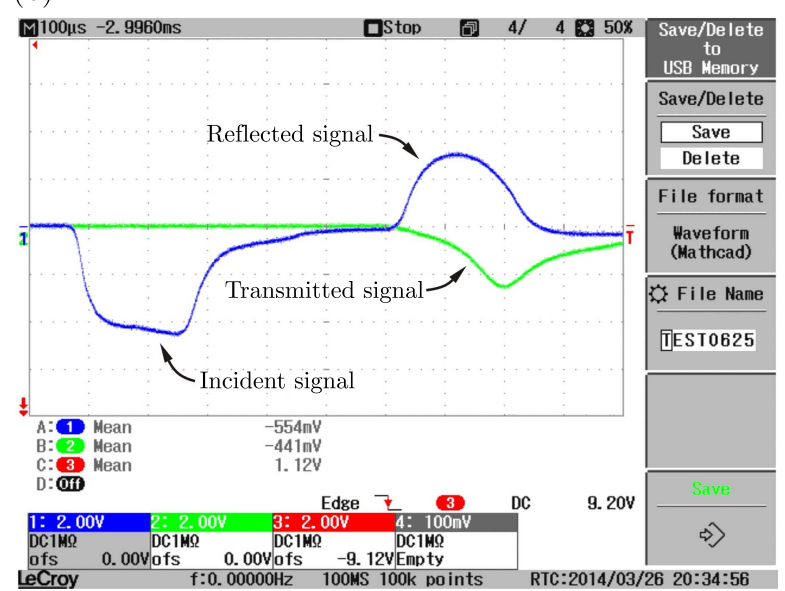

Fig. 6. Raw wave signals measured by strain gauges attached on: (a) aluminium alloy bars,

(b) PMMA bars

Geometry of the rubber specimen was chosen experimentally. At the first stage of those works, the initial specimen length was selected to meet the main methodological requirement of SHPB technique, i.e. the requirement of stress uniformity. The low wave velocity in the rubber specimens make stress equilibrium much more difficult to obtain than in a metal sample. Moreover, the problem is complicated by low strength of rubber, which for improperly long specimen makes the amplitude of the transmitted pulse too weak to be precisely measured. For the aluminium alloy bar set-up, special attention was paid to find a proper specimen length, sufficient loading conditions (striker velocity) and suitable signal gain to obtain a required quality of the transmitted signals for which the signal-to-noise ratio was higher than $25 \mathrm{~dB}$. It was observed that for specimens with a thickness greater than $3 \mathrm{~mm}$ and for striker velocities less than $5 \mathrm{~m} / \mathrm{s}$, the transmitted signal was too weak and had poor quality, although the applied signal gain was relatively high and equal to $500 \mathrm{~V} / \mathrm{V}$. It should be mentioned though that the signals recorded by strain gages glued on the PMMA bars were amplified only with gain $200 \mathrm{~V} / \mathrm{V}$, giving the voltage amplitude in the order of several volts, whereas for the same signal gain the voltage amplitude recorded from the strain gage attached on the aluminium alloy bars was only in the order of several dozen millivolts, depending on striker velocity.

The initial diameter of the specimen was also chosen for the assumed maximal testing conditions: striker impact velocity of $\sim 15 \mathrm{~m} / \mathrm{s}$, strain level of $\varepsilon \approx 1$. The need to determine the diameter of the sample results from the fact that during dynamic testing, elastomer materials deform very easy with the extremely large strain, causing an "escape" of a certain part of the sample material beyond the bar diameter (see Fig. 7). Therefore, by using a high-speed came$\mathrm{ra}$, the deformation process of specimens with various diameters were monitored to assess the correctness of the carried out tests.

Finally, it was assumed that for the comparison purpose, the dimensions of the specimens were the same for both bar systems and were as follows: diameter $6 \mathrm{~mm}$; thickness $\sim 1 \mathrm{~mm}$ (Al 7056-T6) and $\sim 2 \mathrm{~mm}$ (PMMA). Similarly to quasi-static testing, each rubber specimen was pre-compressed dynamically four times, before the final test. 


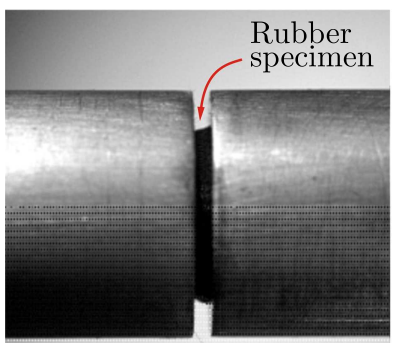

$0 \mu \mathrm{s}$

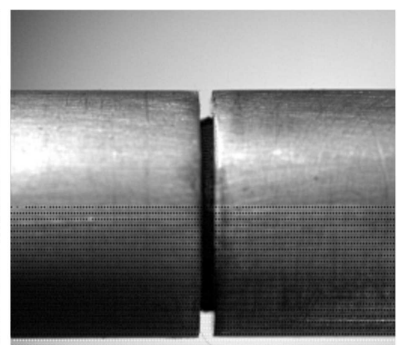

$29.8 \mu \mathrm{s}$

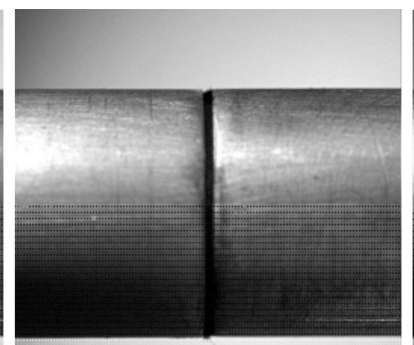

$59.6 \mu \mathrm{s}$

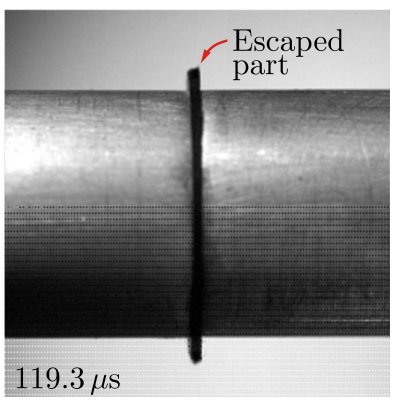

$119.3 \mu \mathrm{s}$

Fig. 7. A sequence of images showing the deformation process of a rubber specimen with diameter $8 \mathrm{~mm}$ and length $1.2 \mathrm{~mm}$

\subsection{Dynamic SHPB tests results}

Verification of the rubber testing procedure at high strain rate loading was based on the assessment of the stress equilibrium state in the specimen for both bars configurations. The stress curves in Fig. 8 represent stress conditions on the front $\sigma_{1}$ and rear $\sigma_{2}$ (dotted line) ends of the specimens for PMMA and aluminium alloy bars. In each case, the impact velocity of the striker bars and specimen length were comparable, and they were about $6 \mathrm{~m} / \mathrm{s}$ and $1 \mathrm{~mm}$, respectively. However, the stress equilibrium state was different for each experiment. The specimen tested with the aluminium alloy SHPB deformed initially non-uniformly, and only after $60 \mu$ s the stress equilibrium was achieved. In the case of the experiment with the PMMA bars, non-equilibrium of stresses was also observed on the specimen interfaces during the initial stage of deformation; however, the non-equilibrium degree was significantly lower. It is, first of all, a result of differences at the rates of strain. Despite a similar impact velocity and specimen length, the strain rate during the experiment with the aluminium alloy bars was higher $\left(\dot{\varepsilon}=5700 \mathrm{~s}^{-1}\right)$ since the sound speed in aluminium alloy bars was considerably higher $\left(C_{o}=5117 \mathrm{~m} / \mathrm{s}\right)$ than in the PMMA bars $\left(C_{o} \approx 1900 \mathrm{~m} / \mathrm{s}\right)$. Moreover, the rise times of the incident wave for both experiments were very different: $12 \mu \mathrm{s}$ for the aluminium alloy and $76 \mu \mathrm{s}$ for the PMMA bars (Fig. 9). As it was mentioned before, a long rise time for PMMA was, on one hand, a result of its damping properties, however, on the other hand, it resulted from application of the wave shaper. It should also be noted that loading duration of the specimen during the PMMA bar experiment was considerably longer $(\approx 290 \mu \mathrm{s})$, whereas in the other case, it was only $126 \mu \mathrm{s}$. It was due to the significant difference between propagation velocity of a viscoelastic wave in the PMMA bar in comparison to the wave velocity in the aluminium alloy bar. Moreover, a constant strain rate was achieved for a relatively long time, as presented in Fig. 10. It should be stated that in the authors' opinion all aforementioned observations are in accordance to the findings by Chen et al. (2000), Zhao et al. (1997), Roland (2006), Song and Chen (2003) and they also prove the validity of the method used to correct the wave attenuation and dispersion effects.

(a)

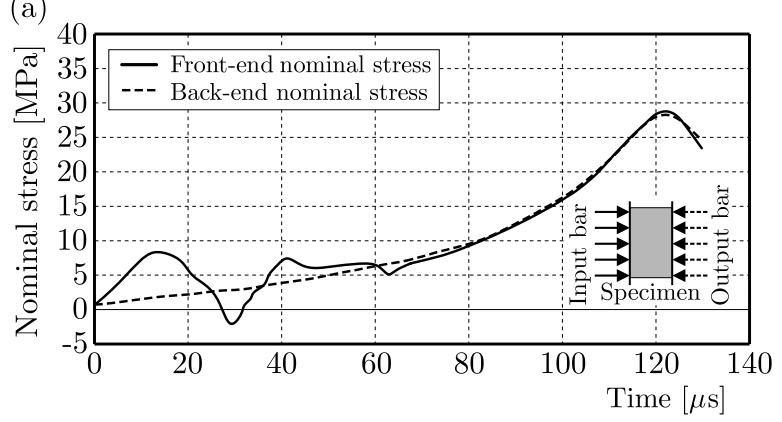

(b)

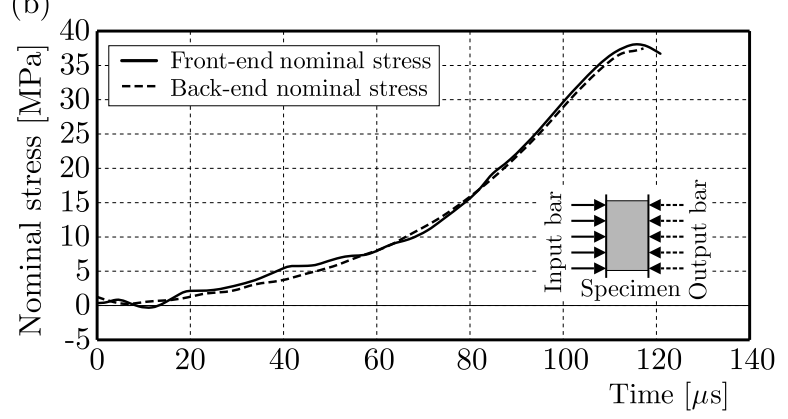

Fig. 8. Comparison of stresses at the front $\sigma_{1}$ and rear $\sigma_{2}$ ends of rubber specimens tested with the use of (a) PMMA bars and (b) Al 7075-T6 bars 

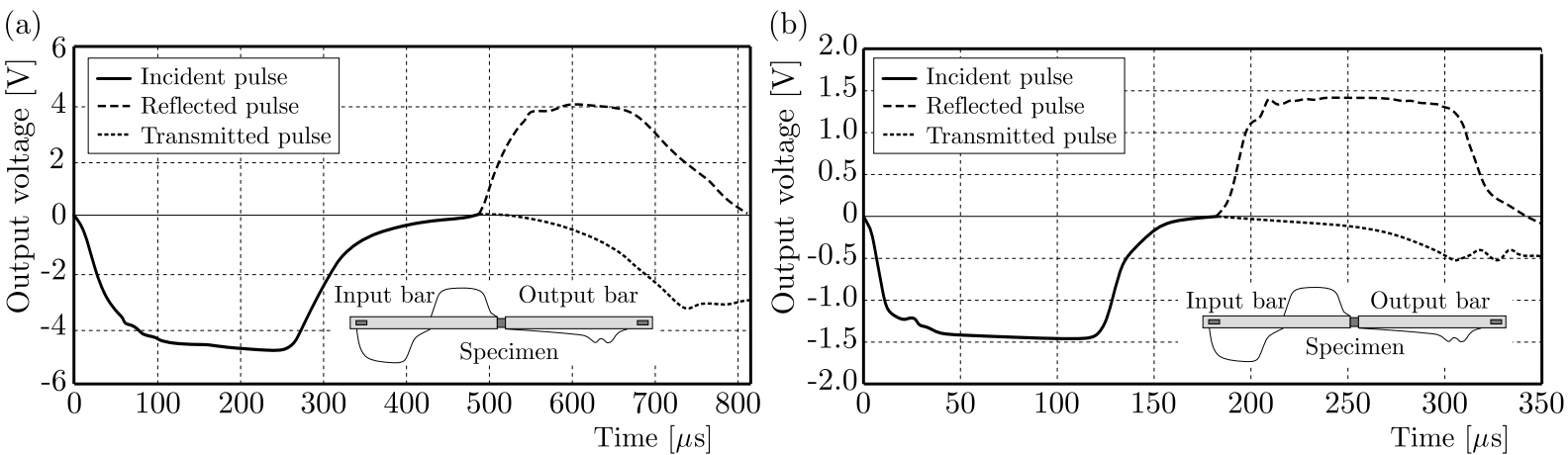

Fig. 9. Incident, transmitted and reflected pulses obtained for (a) PMMA bars and (b) Al 7075-T6 bars

(a)

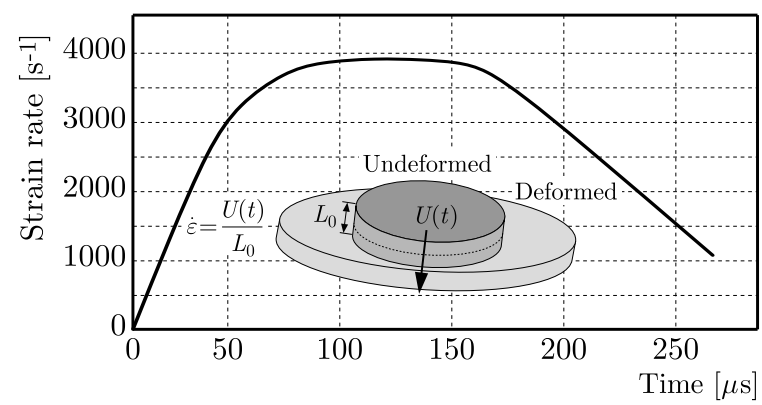

(b)

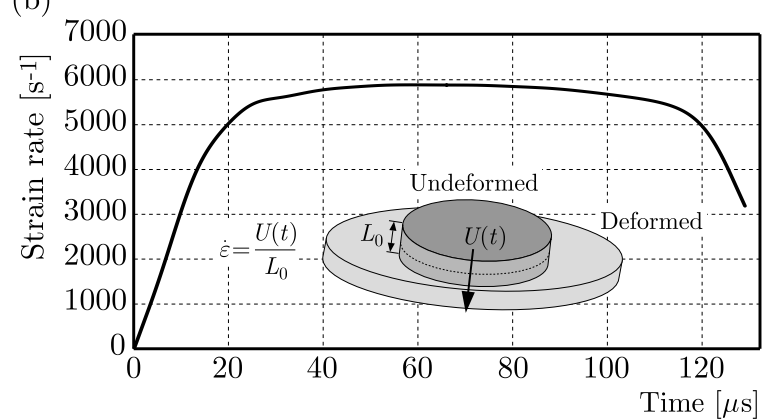

Fig. 10. Strain-rate history in the rubber specimen during SHPB with (a) PMMA bars and (b) Al 7075-T6 bars

During the quasi-static tests, each specimen was compressed several times. The first four were pre-compression tests, whereas the fifth was the main one whose results were taken into consideration. The same approach was followed in SHPB testing and the analogous results were also obtained. One of the specimens was pre-compressed five times for confirming the phenomenon, while the others were pre-compressed three times and tested only once. In Fig. 11, five engineering stress vs. engineering strain curves for the same specimen are presented for the PMMA (a) and aluminium alloy bars system, while in Fig. 12 chosen curves are collected for the comparison purpose. In turn, the summary characteristics for 5 different strain rates are presented in Fig. 13 for quasi-static and dynamic loading conditions.

(a)

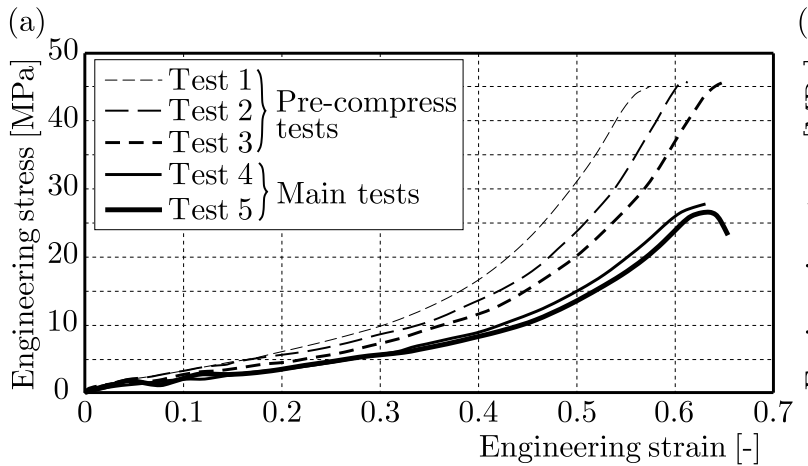

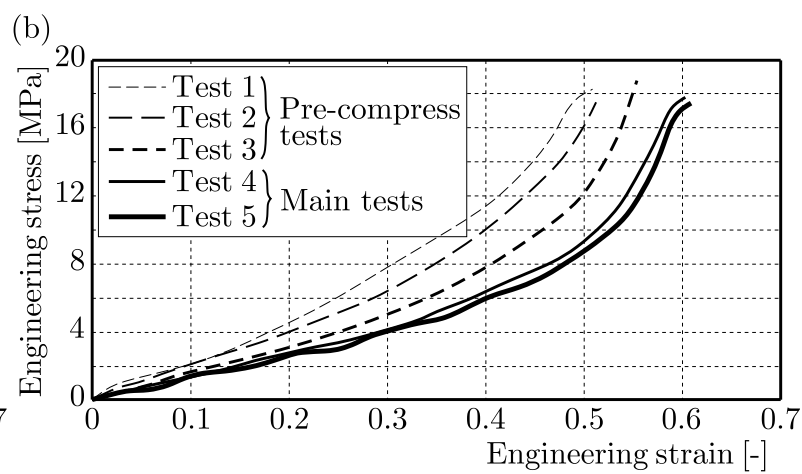

Fig. 11. Stress-strain curves for one specimen with pre-compression in SHPB test with (a) PMMA bars and (b) Al7075-T6 bars

Observing the curves shown in Fig. 11, it can be concluded that the mechanical behaviour of the rubber specimen varies significant during pre-compression tests No. 1, 2 and 3. Tests No. 4 and 5 resulted in stress-strain curves with profiles similar to each other, as it was in the case of quasi-static tests. The necessity of performing pre-compression tests is therefore an 


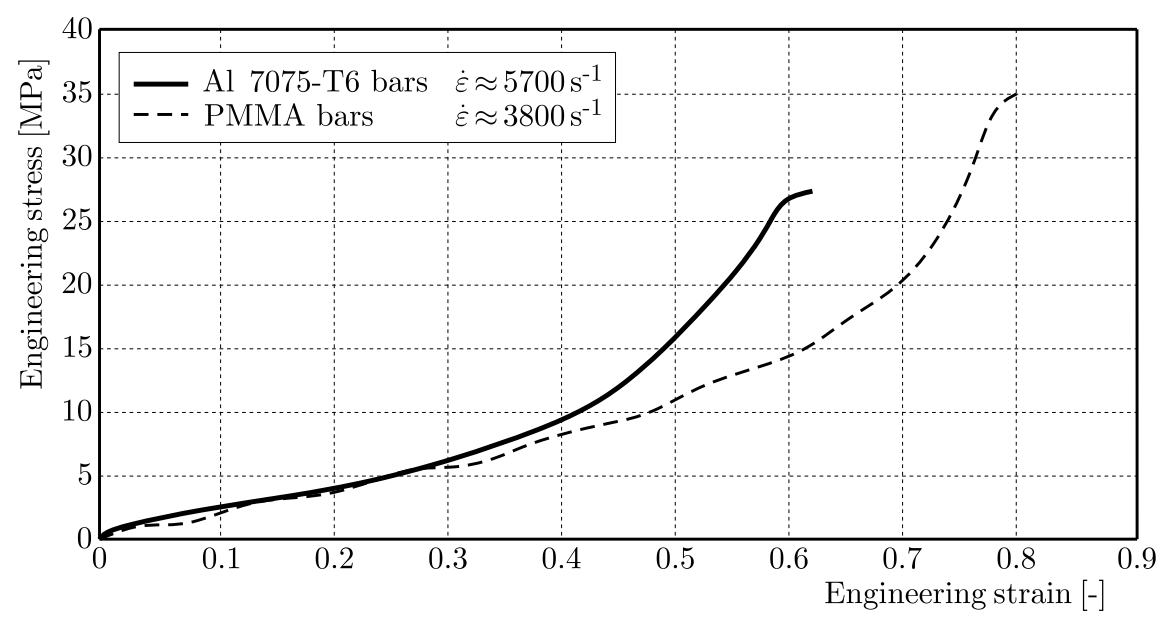

Fig. 12. Engineering stress-strain curves for tested tire rubber samples using SHPB with PMMA and Al 7075-T6 bars

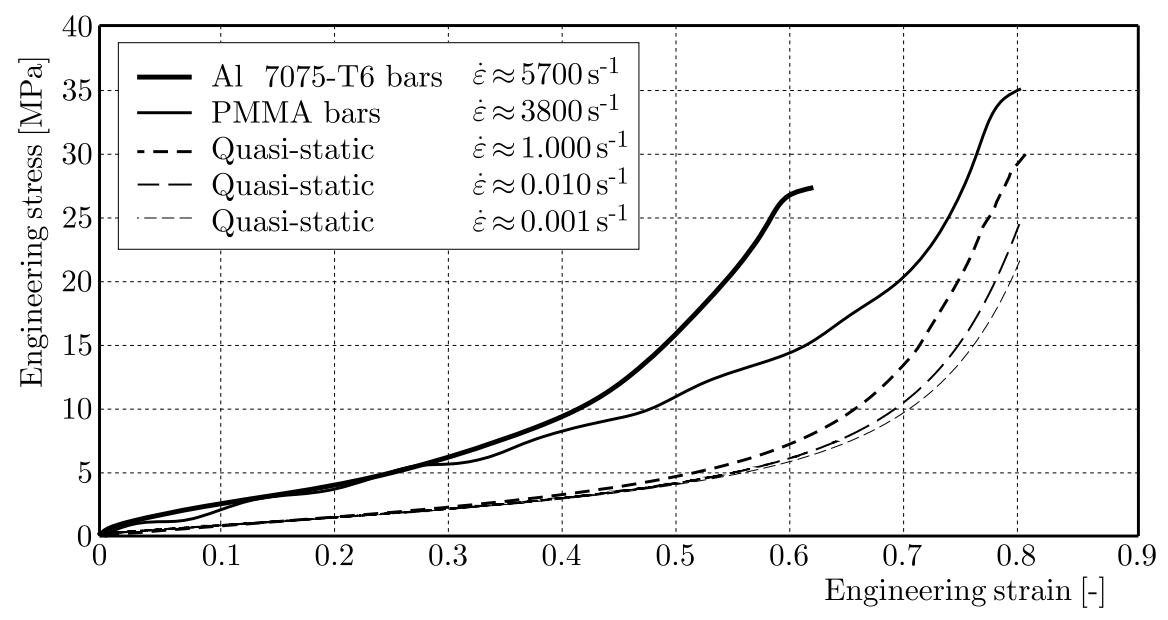

Fig. 13. Summary engineering stress-strain curves for tested rubber material samples

important methodological requirement to achieve valid experimental data from both quasi-static and dynamic tests.

The curves shown in Fig. 12 obtained from the high strain rate experiments suggests that the tested tire rubber is weakly sensitive to the rate of strain. For strains up to 0.3, the stress level is almost the same, despite the fact that experiments were carried out with different strain rates of $3800 \mathrm{~s}^{-1}$ and $5700 \mathrm{~s}^{-1}$, respectively. A difference between the curves appears only after strains larger than 0.3 , suggesting high strain rate sensitivity of the tested rubber. It may also be caused by inertia and friction effects which increase the value of flow stress in principle. However, it is commonly known that rubber and other elastomers are sensitive to the rate of strain (Roland, 2006; Song and Chen, 200, 2005; Chen and Song, 2010). A clear evidence of the strain rate sensitivity of the tested rubber is shown in Fig. 13 presenting a combination of quasi-static and dynamic curves obtained during the testing.

\section{Summary}

The procedure of determining correct mechanical characteristics for the tire material with rubber-like parameters has been presented in a comprehensive way. A uniaxial compression test was carried out under quasi static and high strain rate loading conditions. The obtained results provided evidence on the correctness of the applied testing procedures. 
During testing, a necessity of performing pre-compression tests to achieve valid experimental data both from quasi-static and dynamic tests was highlighted. Moreover, it was proved that high strain rate testing of soft materials with the use of polymeric bars provided several benefits, such as an increased sensitivity of the experimental setup and reduction of mechanical impedance mismatch. However, the use of polymeric SHPB technique required an additional analysis for data reduction, temperature complications and additional restrictions compared to traditional metallic pressure bars. In addition, some methodical requirements guaranteeing the validity of high strain rate rubber testing were pointed out. Among them:

- use of low impedance Al7075-T6 and PMMA material for bars to measure a weak signal, omit the problem with impedance mismatch between the specimen and the bars,

- applying proper shaping of the incident pulse guaranting a uniform stress and constant strain rate within a certain duration of loading,

- appropriate selection of specimen dimensions and experimental conditions to meet the stress equilibrium requirement and to minimalize inertial and friction effects.

Soft material testing, especially with the use of SHPB technique, requires knowledge, time and patience in preparing specimens, apparatus or data processing. Nevertheless, obtaining proper results has great importance in the case of simulation of strongly dynamic problems. Some data obtained during the experiments presented in the paper were used in parallel investigations concerning tire modelling (Baranowski et al., 2016a,b).

\section{Acknowledgements}

The research was carried out under a research grant RMN 723. This support was gratefully acknowledged.

\section{References}

1. Ackland K., Anderson C.H., NGo T.D., 2013, Deformation of polyurea-coated steel plates under localised blast loading, International Journal of Impact Engineering, 51, 13-22

2. BACON C., 1998, An experimental method for considering dispersion and attenuation in a viscoelastic Hopkinson bar, Experimental Mechanics, 38, 242-249

3. Baranowski P., Mazachowski J., Janiszewski J., Wekezer J., 2016a, Detailed tyre FE modelling with multistage validation for dynamic analysis, Materials and Design, 96, 68-79

4. Baranowski P., MaŁachowski J., Mazurkiewicz Ł., 2016b, Numerical and experimental testing of vehicle tyre under impulse loading conditions, International Journal of Mechanical Sciences, 106, 346-356

5. Butt H.S.U, Xue P., 2013, Determination of the wave propagation coefficient of viscoelastic SHPB: Significance for characterization of cellular materials, International Journal of Impact Engineering, 74, 83-91

6. Baranowski P., Malachowski J., 2015, Numerical study of selected military vehicle chassis subjected to blast loading in terms of tire strength improving, Bulletin of the Polish Academy of Sciences Technical Sciences, 3, 4, 1-12

7. Baranowski P., MaŁachowski J., NiezGoda T., 2011, Numerical analysis of vehicle suspension system response subjected to blast wave, Applied Mechanics Materials, 82, 728-733

8. Borkowski W., Motrycz G., 2012, Analysis of IED explosion on carrier road safety, Journal of KONES and Powertrain Transport, 19, 4, 75-82

9. Casem D.T., Fourney W.L., Chang P., 2003, A polymeric split Hopkinson pressure bar instrumented with velocity gages, Experimental Mechanics, 43, 4, 420-427 
10. Chen W., Lu F., Zhou B., 2000, A quartz-crystal-embedded split Hopkinson pressure bar for soft materials, Experimental Mechanics, 40, 1, 1-6

11. Chen W., Song B., 2010, Dynamic characterization of soft materials, Dynamic Failure of Materials and Structures, 1-28

12. Chen W., Song B., 2011, Split Hopkinson (Kolsky) Bar, Design, Testing and Applications, Springer

13. Chen W., Zhang B., Forrestal M.J., 1999, A split Hopkinson bar technique for low-impedance materials, Experimental Mechanics, 39, 81-85

14. Cheng Z.Q., Crandall J.R., Pilkey W.D., 1998, Wave dispersion and attenuation in viscoelastic split Hopkinson pressure bar, Shock and Vibration, 5, 307-315

15. D575-91 AS, 2001, Standard Test Methods for Rubber Properties in Compression, USA

16. DuYle J.F., 1989, Wave Propagation in Structures - An FFT-Based Spectral Analysis Methodology, Springer-Verlag, New York

17. Ellwood S., Griffiths L.-J., PArry D.J., 1982, Materials testing at high constant strain rates, Journal of Physics Engineering: Scientific Instruments, 15, 280-282

18. Franz C.E., Follansbee P.S., Berman I., Schroeder J.W., 1984, High Energy Rate Fabrication, American Society of Mechanical Engineers, New York

19. Gent A.N., 1994, Compression of rubber blocks, Rubber Chemistry and Technology, 67, 549-558

20. Giovanola J.H., 1988, Adiabatic shear banding under pure shear loading: part I, Mechanics of Materials, 7, 59-71

21. Gray III GT., 2000, ASM Handbook: Mechanical testing and evaluation, [In:] Materials Park, Kuhn H., Medlin D. (Edit.), OH: ASM International, 8, 939-1270

22. Helnwein P., Liu C.H., Meschke G., Mang H.A., 1993, A new 3D finite element model for cord-reinforced rubber composites application to analysis of autobomile tires, Finite Elements in Analysis and Design, 4, 1-16

23. Hopkinson B., 1904, The effect of momentary stress in metals, Proceedings of the Royal Society of London, 74, 498-507

24. Hopkinson J., 1872, On the rapture of iron wire by a blow, Proceedings of the Manchester Literary and Philosophical Society, 1, 4-45

25. Janiszewski J., 2012, Testing of Engineering Materials Under Dynamic Loading Conditions (in Polish), Military University of Technology, Warsaw

26. Janiszewski J., Bużantowicz W., Baranowski P., 2016, Correction procedure of wave signals for a viscoelastic split Hopkinson pressure bar, Problems of Mechatronics: Armament, Aviation, Sefety Engineering, 7, 1, 17-30

27. Kim J.H., JEONG H.Y., 2005. A study on the material properties and fatigue life of natural rubber with different carbon blacks, International Journal of Fatigue, 27, 263-272

28. Kolsky H., 1953, Stress Waves in Solids, Oxford University Press, London

29. Lindholm U.S., Yeakley L.M., 1968, High strain-rate testing: tension and compression, Experimental Mechanics, 8, 1, 1-9

30. Malachowski J., Wesolowski M., Krason W., 2007, Computational study of transport aircraft landing gear during touchdown, Journal of KONES and Powertrain Transport, 13, 4, 187-195

31. Meyers M.A., 1994, Dynamic Behaviour of Materials, Johs Wiley and Sons, INC, New YorkChichester-Brisbane-Toronto-Singapoure

32. NAKAJima Y., TAKAhashi F., 2002, Increase of frictional force of rubber block by uniform contact pressure distribution and its application to tire, Rubber Chemistry and Technology, 75, 589-604 
33. Nicholas T., 1981, Tensile testing of Materials at high rates of strain, Experimental Mechanics, 21, 5, 177-185

34. Pouriayevali H., Shim V.P.W., 2012, A constitutive description of elastomer behaviour at high strain rates - A strain dependent relaxation time approach, International Journal of Impact Engineering, 47, 71-78

35. Reid J.D., Boesch D.A., Bielenberg R.W., 2007, Detailed tire modeling for crash applications, International Journal of Crashworthines, 12, 5, 521-529

36. Roland C.M., 2006, Mechanical behaviour of rubber at high strain rates, Rubber Chemistry and Technology, 79, 429-459

37. Roland C.M., Fragiadakis D., Gamache R.M., 2010, Elastomer-steel laminate armor, Composite Structures, 92, 1059-1064

38. Saintier N., Cailletaud G., Piques R., 2006, Multiaxial fatigue life prediction for a natural rubber, International Journal of Fatigue, 28, 530-539

39. Song B., Chen, W., 2003, One-dimensional dynamic compressive behaviour of EPDM rubber, Journal of Engineering Materials and Technology, 125, 294-301

40. Song B., Chen W., 2005, Split Hopkinson pressure bar techniques for characterizing soft materials, Latin American Journal of Solids and Structures, 2, 113-152

41. Sridharan K., Sivaramakrishnan R., 2013, Compressive and shear analysis of rubber block under large strain, American Journal of Applied Sciences, 10, 7, 681-687

42. Szurgott P., Gotowicki P., Niezgoda T., 2012, Numerical analysis of a shaped rail pad under selected static load, Journal of KONES and Powertrain Transport, 19, 1, 407-414

43. Wang L., Labibes Z., Azari Z., Pluvinage G., 1994, Generalization of split Hopkinson bar technique to use viscoelastic bars, International Journal of Impact Engineering, 15, 669-686

44. Zhao H., Gary G., 1995, A three dimensional analytical solution of the longitudinal wave propagation in an infinite linear viscoelastic cylindrical bar. Application to experimental techniques, Journal of the Mechanics and Physics of Solids, 43, 8, 1335-1348

45. Zhao H., Gary G., Klepaczko J.R., 1997, On the use of a viscoelastic split Hopkinson pressure bar, International Journal of Impact Engineering, 19, 4, 319-330

46. Zine A., Benseddiq N., NAit Abdelaziz M., 2006, Rubber fatigue life under multiaxial loading: numerical and experimental investigations, International Journal of Fatigue, 33, 1360-1368 